\title{
Plaster of Paris (P.0.P): Study to Determine the Best Method of Application
}

\author{
Mohamed Maher*, Dilnath Gurusinghe and Ahmed Elgawad \\ Department of Plastic Surgery, Countess of Chester Hospital, UK
}

Submission: December 26, 2016; Published: January 06, 2017

*Corresponding author: Mohamed Maher, Queen Elizabeth Hospital Birmingham- Mendelson Way B152TH, UK

\begin{abstract}
A great deal of surgical interventions in the hand often warrants the use of plaster of Paris (p.o.P) splints. This is true for trauma (e.g. hand injuries, burns) as well as for elective hand surgery (e.g. Dupuytrens' disease, reconstructive surgery). The aim of this immobilization is to protect the anatomical structures repaired and avoid joint stiffness at the same time. This mainly occurs at the metacarpophalangeal joints (MCPJ) and the proximal interphalangeal joints (PIPJ); hence the hand is splinted in a safe or 'intrinsic plus' position, where the MCP is flexed and the PIP extended [1,2].

Objective

To study the effect of placing plaster of Paris (p.o.P) in an elasticized sleeve (Tubigrip ${ }^{\text {TM }}$ - Mölnlycke Healthcare - Sweden) before usage as a splint after hand surgery.
\end{abstract}

\section{Materials \& Methods}

Uniform rectangular shaped splints were made and divided into three groups. A 15-ply splint for all groups was used with plaster width being 10 centimeter $(\mathrm{cm})$. The splints in the test group were placed in the Tubigrip ${ }^{\mathrm{TM}}$ sleeve before immersing in water, while the control group was not (conventional method). In the third group, the splints were placed in standard wool bandage (Figure 1). Tap water with a temperature of $20-25^{\circ} \mathrm{C}$ used to immerse the p.o.P splints in. Each splint was subjected to strength test after the splints had set. All the slabs were made by the senior author using the same left-handed model to maintain our results (Figure 2). The splints were volar splints in the intrinsic plus position. The splints were placed on a fulcrum at the part that corresponds to the wrist, and were subjected to increasing weight being applied to the tips of the splint, and its deflection measured in millimetres ( $\mathrm{mm})$.

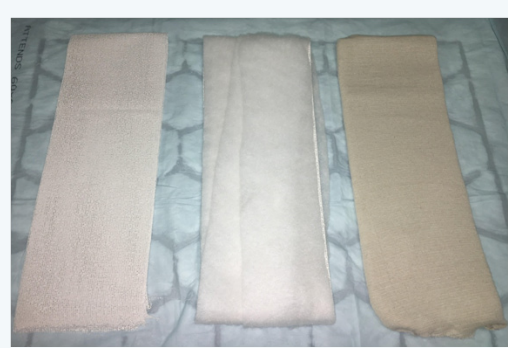

Figure 1: POP splints before immersion; left - standard, centre - with cotton wool, right - with Tubigrip ${ }^{\mathrm{TM}}$.

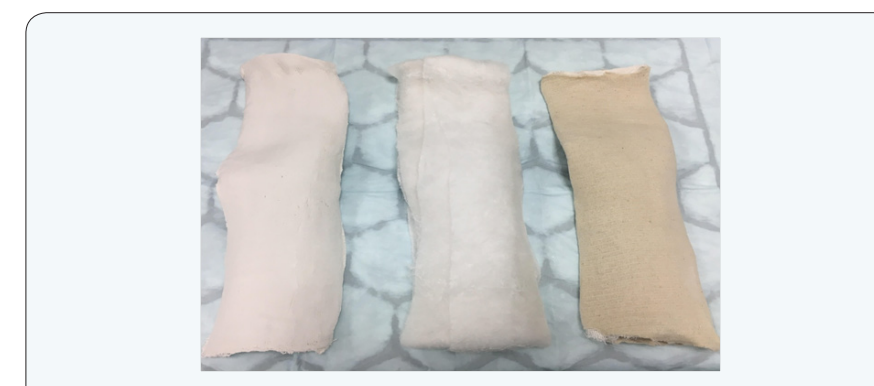

Figure 2: POP after setting; left - standard, center - with cotton wool, right - with Tubigrip ${ }^{\mathrm{TM}}$.

\section{Results}

The weight in grams (gm) of the splints after drying was; p.o.P $234.34 \mathrm{gm}$, splint with wool padding $265.74 \mathrm{gm}$, and p.o.P with Tubigrip ${ }^{\mathrm{TM}} 270.07 \mathrm{gm}$. The deflecting weight applied at which the splints started to bend was $2500 \mathrm{gm}$ and the amount of deflection noted was least in the Tubigrip ${ }^{\mathrm{TM}}$ group with $0.21 \mathrm{~mm}$, p.o.P with wool bandage $0.30 \mathrm{~mm}$, and plain p.o.P with $0.35 \mathrm{~mm}$.

\section{Discussion}

The chemical composition of p.o.P is calcium sulphate hemihydrate that is used to coat plain weave gauze. P.o.P splints are a very common practice in hand surgery and they aim at immobilizing the hand and wrist while at the same time preventing joint stiffness from prolonged immobilization $[3,4]$. 
This is achieved by placing the hand and wrist in the 'intrinsic plus' position; in which the MCP is in $70-90^{\circ}$ flexion with the PIP in $0-20^{\circ}$ extension. This is aided by the placing the wrist in $30-40^{\circ}$ extension $[1,2]$. P.o.P slabs are known to be strong in compression but have weak mechanical properties in tension thus loosing rigidity slowly over time [5].

Previous studies of p.o.P strength reinforcement were centered on increasing the layers or altering the design of the slab. Taams et al. [6] experimented with the use of a slab made of 30 layers of p.o.P, and reached the conclusion that despite being strong, they were equally heavy [6]. Hamilton et al. and Stewart et al. [7,8] have modified the shape of the volar slab by adding two longitudinal ridges along the course of the slab to it to strengthen its overall performance $[7,8]$. Hamilton et al. reached a conclusion that the simple ridged slab is stronger than the conventional molded slab requiring a mean load to failure of $385 \mathrm{~N}$ in comparison to $72 \mathrm{~N}$ [7]. However, Stewart et al. [8] found that the 10 layer reinforced slab withstands $152 \mathrm{~N}$ prior to failure [8].

\section{Conclusion}

We aimed at retaining the tension property by placing our p.o.P slabs in a Tubigrip ${ }^{\mathrm{TM}}$ sleeve before applying it to the patients hand and allowing it to set. We found it to be stronger in terms of the forces required to bend at the wrist in comparison to the conventional method or the wool bound slabs.

\section{Acknowledgement}

We would like to thank Stuart Eccles in EBME department at the Countess of Chester Hospital for his efforts in this work.

\section{References}

1. James JIP (1962) Fractures of the proximal and middle phalanges of the fingers. ActaOrthop Scand 32: 401-412.

2. James JI (1970) Common, simple errors in the management of hand injuries. Proc SocMed 63(1): 69-71.

3. Sprague BL (1975) Proximal interphalangeal joint injuries and their initial treatment. J Trauma15: 380-385.

4. Watson KH, Weinzweig J (1993) Stiff joints. In: Green DP, Hotchkiss RN, Pederson III WC, editors. Green's operative hand surgery. Churchill Livingstone, Edinburgh, UK.

5. Schmidt VE, Somerset JH, Porter RE (1973) Mechanical properties of orthopaedic plasterbandages. J Biomech 6(2): 173-185.

6. Taams KO, Ash GJ, Johannes S (1996) Maintaining the safe position in a palmar splint. The “double-T” plaster splint. J Hand Surg (Br) 21(3): 396-399.

7. Hamilton SW, Aboud H (2009) Finite element analysis, mechanical assessment and material comparison of two volar slab constructs. Injury 40(4): 397-399.

8. Stewart T, Cheong W, Barr V, Tang D (2009) Strong and light plaster casts?. Injury $40(8):$ 890-893.

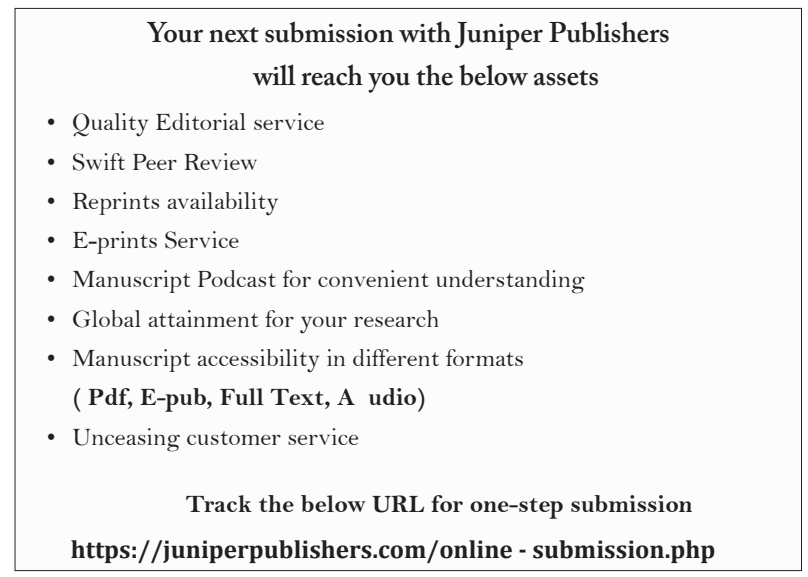

